\title{
Seismic Response Analysis for Shallow Buried and Unsymmetrical
}

\author{
Loading Tunnel \\ LI Lin ${ }^{1}$, WANG Ke Si ${ }^{1}$, YANG Du Gong ${ }^{1}$, PENG Sheng Tao ${ }^{2}$, LI Lin ${ }^{2^{*}}$ \\ (1.School of Civil Engineering, Sichuan Agricultural University, Dujiangyan 611830, \\ China;2.Department of Architecture and Urban Planning, Guangan Vocational \& College, Guangan \\ 638000, China. )
}

Keywords: tunnelling engineering; shallow unsymmetrical loading tunnel; seismic time history analysis; seismic response character of tunnel

Abstract: Based on analyzing the damage feature of shallow buried and unsymmetrical loading tunnel, this paper studies the seismic reaction characteristics of this kind of tunnel via numerical simulation and comparison of the similar tunnel bearing symmetric load. The results indicate that the tunnel is more likely to get damage for its shallow bury ground and unsymmetrical load; there exists obvious acceleration amplification with the growth of the ground height, and this phenomenon is more significant on the ground surface; normally, the distribution of the lining cross-section's internal forces is oval-shaped, while the unsymmetrical load makes the inner force nonuniform and leads to great inner force. It is great to recognize the seismic response characters of shallow tunnels through the study results and it provides reference for the similar projects.

\section{Introduction}

"5.12" Wenchuan and other major earthquakes show that tunnels which have good surrounding rock and are deep buried have good aseismic quality, but when the seismic intensity is great, the quality of the surrounding rock is poor, the shallow buried tunnels undertake serious damage ${ }^{[1]}$; the entrance part has such characteristics: shallow bury ground, poor surrounding rock and unsymmetrical load, which makes this part bears many seismic damage. In the 1923 Tokyo 7.9 earthquake, many tunnels in this regions suffer from damage, unsymmetrical loading tunnels in poor ground bears more significant damage including a lot of cracks appears in lining and serous deformation of the lining; In 1995, the 7.2 Kobe earthquake makes more than $10 \%$ of the tunnels in this area occurs seismic hazard, a of cracks emerge in the lining of Shanyang Shinkansen Malacca tunnel $^{[2]}$. In the 1999 Taiwan ChiChi earthquake, survey has been conducted to investigate the 44 tunnels in the range of $25 \mathrm{~km}$ from the earthquake fault, which showed that 25 percent suffer from serious damage, 20 percent get middle damage, and tunnel with slight damage take up for 55 percent, and most of these damage locate at the entrance part ${ }^{[3]}$; In the 2008 Wenchuan big earthquake, a lot of damage cases is related to entrance section, shallow bury, and unsymmetrical loading, Taoguan tunnel is such an example, after earthquake, the tunnel portal is damaged seriously and there were lot lining cracks, just as the Fig.1 shows. Besides, Longchi tunnel locates in the middle of Dujiangyan to Longchi, at the entrance of the tunnel, there is obvious unsymmetrical loading effect and the quality of surrounding rock is poor, the damage of the earthquake is mainly concentrated in the tunnel entrance, different types of cracks emerge in the lining, like the longitudinal, circumferential through crack and oblique crack, some part of the concrete block out and the steel is exposed, the earthquake damage as shown in Fig. $2^{[4][5][6]}$. 


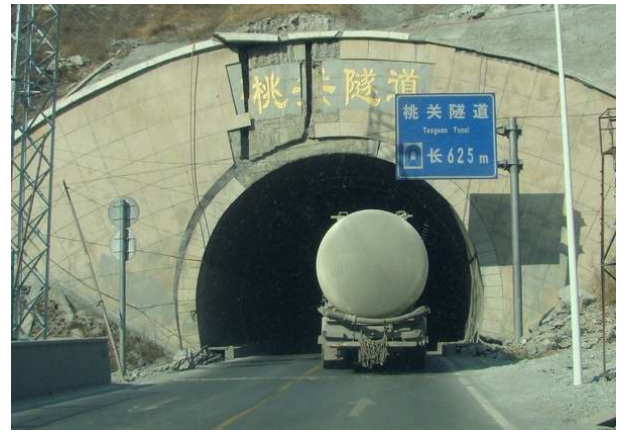

Fig 1. The damage of the Taoguan tunnel at the entrance

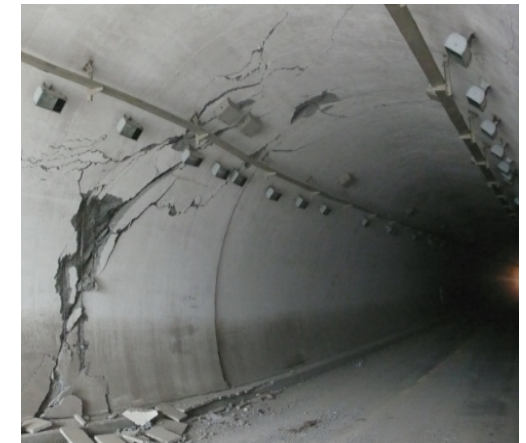

Fig 2. Damage of the side wall at tunnel portal of Longchi tunnel

In view of the above, this paper analyzes the seismic response of shallow buried and unsymmetrical loading tunnel at the portal section, which is based on the dynamic time history numerical simulation, this analysis includes the dynamic response characteristics of the acceleration, the internal force of the tunnel structure, and provides reference for the aseismic design of the similar projects.

\section{dynamic model and parameter}

\section{dynamic simulation model}

This simulation model is based on the entrance portal of longxi tunnel and focuses on the effect of shallow bury ground and unsymmetrical load, the model is showed in Figure 3 . The slope ratio is $1: 2$, the artificial boundary is Sticky boundary which is obtain by setting up the element with the same property of ground element around the ground-structure model to absorb the seismic wave from the model.

\section{mechanical parameters of rockmass}

This part of ground is mainly consist of Jinning granite, the fault section is filled with granite block and crushed stone and soil. Considering the elements in this simulation is under low strain rate, the dynamic mechanical parameters of the rock are not much different from the static mechanical parameters, so this model uses the static mechanical parameters, the specific calculation parameters are shown in Tab. $1^{[6]}$.

Tab.1 Properties of intact rock material

\begin{tabular}{cccccc}
\hline $\begin{array}{c}\text { Types of the } \\
\text { surrounding ground }\end{array}$ & $\begin{array}{c}\text { Density } \\
/\left(\mathrm{kg} \cdot \mathrm{m}^{-3}\right)\end{array}$ & $\begin{array}{c}\text { Elastic Modules } \\
/ \mathrm{GPa}\end{array}$ & $\begin{array}{c}\text { Cohesion } \\
/ \mathrm{MPa}\end{array}$ & $\begin{array}{c}\text { Internal friction } \\
\text { angle/( }\left(^{\circ}\right)\end{array}$ & $\begin{array}{c}\text { Poisson's ratio } \\
\text { rockmass }\end{array}$ \\
\hline 2300 & 0.8 & 0.5 & 34 & 0.32 \\
\hline
\end{tabular}

\section{mechanical damping}

In this dynamic numerical simulation, Rayleigh damping has been used which is often utilized in engineering projects, and the Rayleigh damping must choose intermediate frequency. For geologic bodies, the damping is generally independent of frequency, and the intermediate frequency uses the middle values appear in the numerical simulation. Damping matrix [C] in dynamic equation is related to $[\mathrm{K}]$ and mass matrix $[\mathrm{M}]$, the relationship is showed by the following formula ${ }^{[6]}$.

$$
C=\alpha M+\beta K
$$

$\alpha 、 \beta$ is the Mass ratio of damping coefficient and stiffness proportional damping coefficient. 


\section{Ground motion parameters}

Longxi tunnel locates at VIII degree seismic intensity area, the input seismic wave is Wenchuan earthquake wave and the acceleration peak value is $0.3 \mathrm{~g}$. The input direction of seismic wave is mainly vertical to the tunnel axis, and the acceleration time history curve is shown in Figure 4.

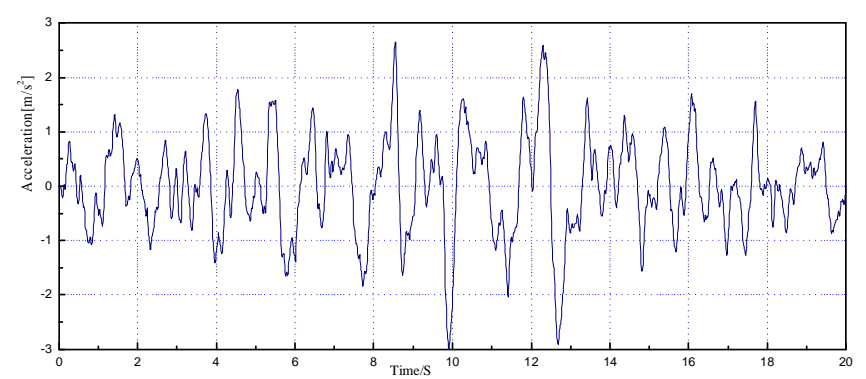

Fig.4 wenchuan seismic wave of dynamic calculation

\section{Analysis of seismic response of tunnel}

According to the layout of the monitoring points of the acceleration of the Fig.5, the amplification ratio and the internal force distribution of the unsymmetrical loading tunnel are obtained after the input of seismic wave.

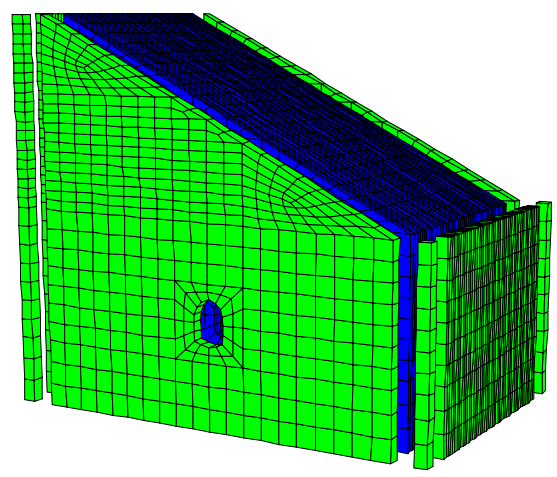

Fig.3 dynamic calculation model and boundary conditions

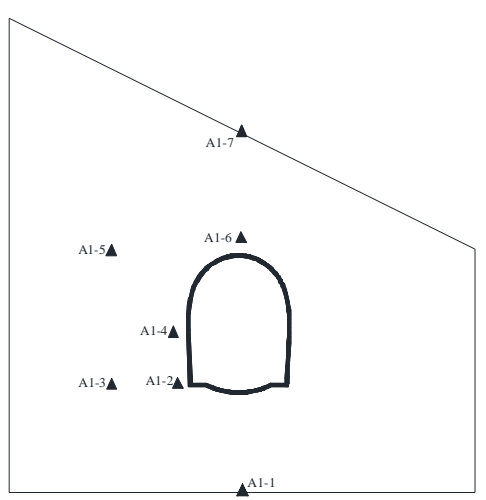

Fig.5 Distribution of monitoring locations

\section{Acceleration response characteristics}

One of the main response characteristics of ground motion response is the acceleration response characteristics, the acceleration response (A1-6、A1-7)at the top and the arch crown of the symmetrical loading and unsymmetrical loading models are obtained which are showed in Figure $6 \sim 9$ 。 These figure shows that the acceleration response of the symmetrical and unsymmetrical loading tunnels share the same characteristics, which tells that the bias loading does not affect the acceleration response. Besides, the peak acceleration value response at the top of model is greater than the value at the arch crown in the two cases, and the peak acceleration at the top model in the unsymmetrical loading model is greater than the value of the symmetrical model, this indicates that the acceleration amplification trend is more obvious with the growth of ground height and the acceleration amplification is greater in the unsymmetrical loading model because the existence of the slope. 


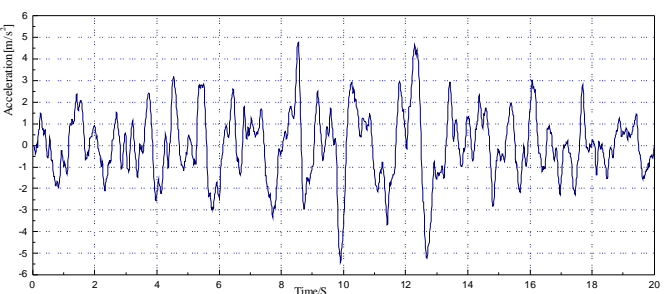

Fig.6 Time-history of acceleration at the arch crown of symmetrical loading tunnel 1 (A1-6)

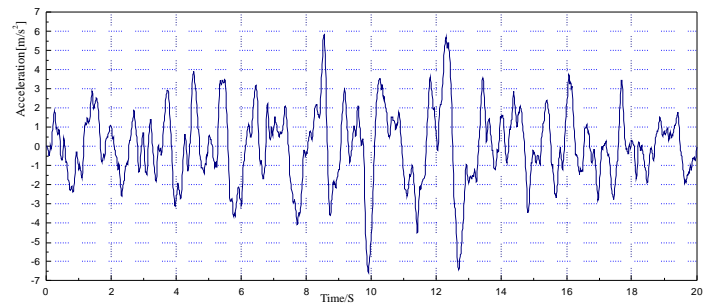

Fig.8 Time-history of acceleration in the top of the symmetrical loading tunnel (A1-7)

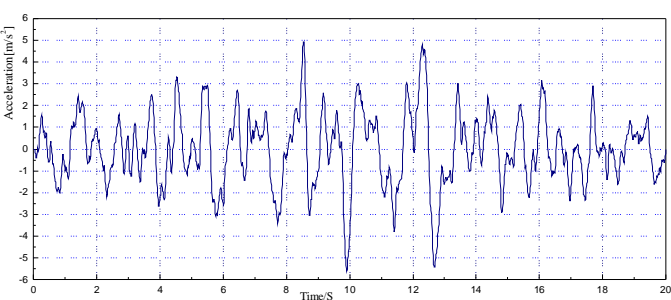

Fig.7 Time-history of acceleration at the arch crown of unsymmetrical loading tunnel 1 (A1-6)

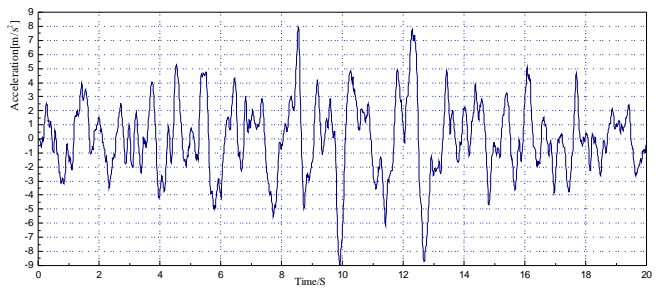

Fig.9 Time-history of acceleration in the top of the unsymmetrical loading tunnel (A1-7)

\section{The inner force of the tunnel structure}

The distribution characteristics of the structure's inner force is one of the main factors affecting the design of aseismic measures. The dynamic response of the inner force is more important for the unsymmetrical loading tunnels, because the static loading is unsymmetrical. Through this simulation, the moment and axial force of the tunnel structure under symmetrical and unsymmetrical loading is showed in the table 2 and table 3.

From the results in the table 2 and table 3 ,show that some part the structure will be in tension, the inner force value is great at the left and right arch waist and foot, the inner force of symmetrical loading tunnel is anti-symmetric to the axis of the cross section, while the tunnel under unsymmetrical loading does not share this character and the inner force is greater at the side bearing more loading, which shows that this part is the control section in the aseismic design.

Tab.2 moment extreme distribution of tunnel structure (unit: $K N \bullet m$ )

\begin{tabular}{|c|c|c|c|c|c|c|c|c|}
\hline Tunnel & Vault & $\begin{array}{l}\text { Arch } \\
\text { bottom }\end{array}$ & Left wall & Right wall & Left arch waist & $\begin{array}{c}\text { Right arch } \\
\text { waist }\end{array}$ & Left foot & Right foot \\
\hline $\begin{array}{c}\text { symmetrical } \\
\text { tunnel }\end{array}$ & -8.8 & 4.7 & -10.9 & 10.9 & -131.3 & 131.3 & -179.6 & 179.6 \\
\hline $\begin{array}{c}\text { unsymmetrical } \\
\text { tunnel }\end{array}$ & -16.9 & 6.4 & -28.5 & 12.7 & -298.9 & 201.3 & -257.9 & 207.2 \\
\hline
\end{tabular}

Tab.3 axial force extreme distribution of tunnel structure (unit: $K N$ )

\begin{tabular}{cccccccccc}
\hline \multirow{2}{*}{ Tunnel } & Vault & $\begin{array}{c}\text { Arch } \\
\text { bottom }\end{array}$ & Left wall & & Right wall & Left arch waist & $\begin{array}{c}\text { Right arch } \\
\text { waist }\end{array}$ & Left foot & Right foot \\
\hline $\begin{array}{c}\text { symmetrical } \\
\text { tunnel }\end{array}$ & -37.12 & 37.12 & -202.17 & 202.17 & -969.3 & 969.3 & -1109.27 & 1109.27 \\
\hline $\begin{array}{c}\text { unsymmetrical } \\
\text { tunnel }\end{array}$ & -99.27 & 100.65 & -810.71 & 680.71 & & -2404.37 & 1804.06 & -2189.64 & 1789.56 \\
\hline
\end{tabular}




\section{Summary}

In this paper, numerical simulation has been taken to investigate the seismic response of the tunnel under unsymmetrical loading and the results are been compared with the symmetrical loading tunnel, this research get these conclusions:

(1)Shallow buried tunnel is more likely to get damaged for its shallow bury ground and unsymmetrical loading, and this section is the main considerable part in the aseismic design.

(2)The acceleration amplification trend is more obvious with the growth of the ground height, unsymmetrical loading does not affect this trend, while it affect the value of the amplification compared with the symmetrical loading at the same height.

(3)As for the inner force of the structure, some part the structure will be in tension for the unsymmetrical load, the inner force value is rather great at the left and right arch waist and foot, the inner force is anti-symmetric when the load is symmetric, while the unsymmetrical loading tunnel get greater inner force on the bias loading side, and this part should be the control section in the aseismic design.

\section{References}

[1] LI Lin, HE Chuan, GENG Ping, et al. Large-scale shaking table test for shallow-buried unsymmetrical tunnel[J]. Chinese Journal of Rock Mechanics and Engineering, 2011, 30(12): 2 540-2 548.

[2] JSCE.The1995 Hyogoken-Nanbu earthquake[J].Japan Society of Civil Engineers,1996,81(3): $38-45$.

[3] WANG W L,et al.Assessment of damage in mountain tunnels due to the Taiwan Chi-Chi Earthquake[J].Tunneling and Underground Space Technology.2001,16:133-150.

[4]WANG Mingnian,CUI Guangyao,LIN Guojin. Reconnaissance and analysis of highway tunnels under Wenchuan earthquake [J].xinangonglu 2009.4:41-46

[5] Wang Zhengzheng.Nonlinear seismic damage response of tunnel structure across fault.[D].Chengdu: SouthWest JiaoTong University,2007

[6] Li Lin. Research on seismic response and seismatic design of tunnel crossing fault.[D].Chengdu: SouthWest JiaoTong University,2014. 